\title{
Design and Modelling Process of Soil Improvement with Concrete Strengthening Elements
}

\author{
Kristóf Lődör ${ }^{1 *}$, Balázs Móczár ${ }^{1}$ \\ ${ }^{1}$ Department of Engineering Geology and Geotechnics, Faculty of Civil Engineering, Budapest University of Technology and \\ Economics, H-1111 Budapest, Műegyetem rkp. 3., Hungary \\ * Corresponding author, e-mail: lodor.kristof@epito.bme.hu
}

Received: 02 November 2019, Accepted: 14 January 2020, Published online: 18 February 2020

\begin{abstract}
In recent decades due to the development and diversification of construction technologies, soil improvement procedures became a competitive and cost-effective alternative to increase the load-bearing capacity of the subsoil, while reducing deformations of the structure. Attributed to urbanization, lands with insufficient soil bearing capacity are becoming construction sites, for which it is essential to influence or increase the bearing capacity of the subsoil for the safety and compatibility of structures. Soil reinforcement with concrete elements is used in more and more construction project in Hungary. The structural behavior of traditional pile foundation is well known, and adequate standards are available during the planning process. On the other hand, soil improvement procedures, in our case for the design of rigid inclusion foundation no standards are available only guidelines and recommendations. Because of that in almost all cases, the design phase includes numerical modelling, which is used to prove the efficiency of the system and receive a more accurate picture of the real structural behavior.
\end{abstract}

Keywords

deep foundation, soil improvement, rigid inclusion, pile, 3D modelling, improvement factor

\section{Introduction}

The lack of suitable construction plots with adequate subsoil conditions causes that areas which were previously considered as unsuitable for construction are reviewed nowadays as possible development areas. This results in the need for subsoil interventions in these regions, which can provide structural stability and bridging the settlement problems.

Compared to other soil reinforcement methods, soil improvement with concrete reinforcement elements, also known as rigid inclusion foundation method, is a foundation technology that is fast, does not require large quantities soil replacement, though greatly reduces structural deformation. [1] Because of that, we can observe strict regulations for structural settlement. The system results in a complex soil-structure interaction where the concrete stiffeners and base plate are not directly connected. A well-compacted load-bearing transfer layer is placed between the piles and the base plate, which transmits the superstructure loads with an arching effect to the reinforcing elements, so in them only normal stresses are awakening.

In 2005, in France within the framework of ASIRI project a research and development program was launched, during which rigid inclusion foundation systems behavior was studied by field measurements and numerical simulations. With the help of them a design guide, rather a guideline was written which gives an insight into the complex behavior of the system. [2]

The rigid inclusion soil improvement system is widely used in all soil types. However, in economic terms, it is primarily effective in case of soils with low bearing capacity such as: clay, sludge and peat. It is widespread among structures where the possible load intensity spread over a large area as well as the structure is sensitive to settlement differences. For example:

- Industrial and agricultural buildings (grain and sugar silos)

- Tanks (water, oil and chemical reagents) [3]

- Embankment foundations (motorways, railways)

- Heavy-duty hall floor foundation

With the introduction of Eurocode, structures earthquake-proof dimensioning affects the choice of foundation technology. The competitiveness and cost effectiveness of the foundation technique; rigid inclusion compared 
to traditional deep foundations, is clearly visible in case of earthquake design. Because no additional stresses are transferred to the base plate and to the reinforcing elements, the separating bearing layer can move independently of the reinforcing elements.

\section{Load transfer mechanisms}

During rigid inclusion the concrete elements improve the weak compression-prone subsoil's physical parameters such as the load-bearing capacity, to reduce deformation of the structure. Between the stiffeners and the base plate there is no direct load transfer, a well-compacted, granular load transfer layer separates the two structural units, thereby securing free movement of foundation and superstructure relative to each other. The reaction forces are not only absorbed by the concrete reinforcing elements, but also a significant proportion transferred to the subsoil due to the plate-like behavior of the bedding layer. [4]

\subsection{Load transfer in the platform}

The columns in rigid inclusion foundation system are not structural elements, which is fundamentally different to the classic piled raft foundation concept. The column heads punch into the load transfer layer and two typical failure modes are possible, i) Prandtl failure diagram and ii) shear cone type failure mode. [2] The LTP (Load Transfer Platform) is responsible to transmit the structural loads into the inclusion heads and into the soil between the columns. The LTP should have a suitable thickness and should be well compacted, so within the layer an arching effect (as it can be seen in Fig. 1.) can be achieved, thereby giving the reinforcing elements a greater load than their surface ratio. In this way the stiffened subsoil will suffer a much lower settlement, while a significant part of the stiffeners' loaded is transmitted to the load-bearing layer.



Fig. 1 Load distribution (arching effect) within the load transfer platform [1]

\subsection{Load transfer behavior of the inclusions}

The load transfer behavior of the inclusions is the same as in case of pile foundation. The structural elements counterbalance the loads by shaft and base resistances. The purpose is to increase load-bearing capacity while reducing settlements. In case of rigid inclusion, over the upper part of the reinforced soil, the soil settles to a greater extent than the inclusions, whereas at the base the inclusions settle more than the soil. A depth therefore exists where both soil and inclusions settle to the same extent, this is known as the neutral plane. In the upper part, this effect takes the form of a negative friction loading the inclusion, until reaching a maximum compressive load at the neutral plane. Negative skin friction (NSF) is in fact a downward friction imposed on foundation pile shaft as a result of subsoil settlement. This causes additional load to be transferred to the piles. Axial load-distribution inside a rigid inclusion in case of negative skin friction is shown in Fig. 2. Combarieu [2] went on to define a radial variation law for vertical stress at height $z$, by introducing the notation of downdrag effect of soft soil around the inclusion. [2]

There are many conventional methods to determine the critical height $\left(h_{c}\right)$, which considers the negative skin friction. The intensity of this negative friction can be calculated based on the following relation:

$$
F_{N}=2 \pi r_{p} \int_{0}^{h_{c}} K \tan \delta \sigma_{v}^{\prime}\left(z, r_{p}\right) d z,
$$

where $r_{p}=$ inclusion radius; $K=$ earth pressure coefficient; $\tan \delta=$ coefficient of soil-pile friction; $\sigma_{v}^{\prime}\left(z, r_{p}\right)=$ effective vertical stress at the inclusion contact in the final state, while taking into account the downdrag effect.



Fig. 2 Axial load-distribution inside a rigid inclusion [2] 


\section{Available design procedures}

Soil improvement with concrete reinforcing elements has no generally accepted uniform calculation procedure, even today. Each national standard only provides guidance and suggestions for the design of structural components. During the tests various simplifications and assumptions should be applied. The layout of each procedure follows the structure of the foundation system, which means that the stiffener must be verified separately from the design of the load-bearing bedding layer. In this calculation methods including geometric parameters of structural elements, determination of the material and thickness of the load transfer platform, if necessary, defining the type of geo-synthetic reinforcements. After the design of the structural elements, the stiffened soil environment has to be checked. The basis of the available design procedures was provided by industrial and laboratory tests as well as based on the results of full-scale physical experiments. [5]

The first step is to determine the required thickness $(H)$ of the load transfer layer definition, for which some basic concepts must first be defined. As a starting point, the stiffeners which are going to be used should be specified diameter $(D)$, raster spacing (axial distances a and b), and number of pieces $(n)$, in addition we consider the base area $(A)$ and a design value of the load acting on the upper plane of the plate $\left(q_{0}\right)$. The following concepts can be defined by the mentioned geometrical parameters:

- Ratio of useful area $(\alpha)$, which is the fraction of the total area of the piles and the total area of the base slab.

- Efficiency Factor: The load-bearing ratio of the piles relative to the load.

The width of the field at the top of a properly compacted load distribution layer, assuming an internal friction angle of $40^{\circ}$ to $45^{\circ}$ (which is the inclination of the cone):

$d=D+2 H$.

Based on this, the surface per reinforcing element:

$A_{R I}=\frac{d^{2} \pi}{4}$.

The useful can be calculated as follows:

$\alpha=\frac{A_{R I}}{a \cdot b}$.

With industrial and laboratory experiments the ratio of useful area has been determined, the relationship between efficiency factor and the thickness of the load distribution layer as well.
Furthermore, the effect of internal friction angle of the filler material on the settlements and on the efficiency of load transfer was evaluated. The most important results of the experiments are summarized in Figs. 3. and 4. (where $s=$ grid spacing).

After determination of the required thickness of the load bearing layer, according to the initial layout of the stiffening elements the second step is the evaluation of load bearing capacity of the stiffened subsoil with the knowledge of the piles load bearing ratio (check of the concrete strengthening elements).

After an examination of the structural elements of the foundation system, the settlement evaluation of the structure should be carried out as described in the literature. The oedometric modulus $\left(E_{\text {oed }}\right)$ of the native soil and knowing the oedometric modulus $\left(E_{c}\right)$ of the stiffening elements calculation of the compression characteristic of a homogenized soil environment $\left(E_{e q}\right)$ can be calculated as follows [5]:

$E_{e q}=\alpha \cdot E_{c}+(1-\alpha) \cdot E_{\text {oed }}$.

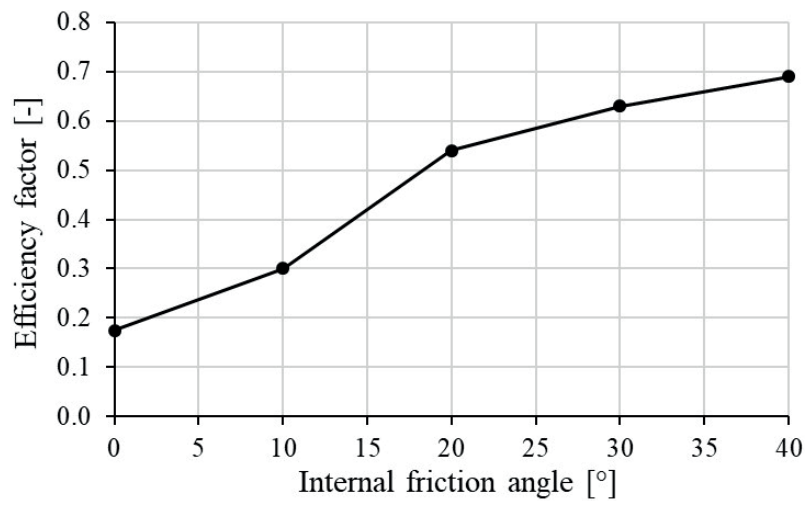

Fig. 3 The relationship between the internal friction angle of the load transfer platform and the efficiency factor [5]

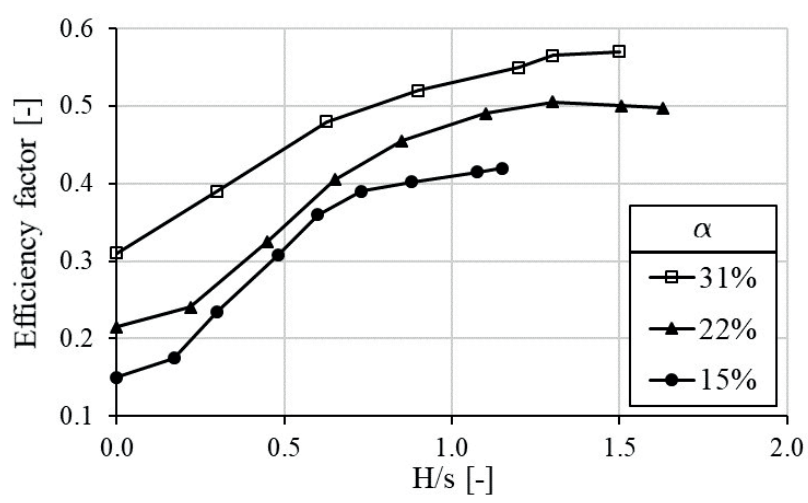

Fig. 4 Effect of the ratio of the bedding layer and the grid spacing on the efficiency factor [5] 


\section{Finite element modelling of the system}

The detailed structural behavior of the foundation system was analyzed with Plaxis 3D geotechnical finite element software, which provides an opportunity to analyze soil-structure interaction. Due to the complexity of subsoil strengthening with this method 2D plane strain modelling is only possible with a lot of geometrical simplifications, which thus does not work properly results for a complete analysis of the structural elements. The most important aspect is the material model, which describes the behavior of the soil environment. The parameters should be carefully selected for the material model. Another important problem is to exactly define the geometry of the structural elements.

\subsection{Modelling of soil behavior}

In finite element calculations the behavior of soil layers can be defined by different material models (there are also built-in and user defined material models). It is well known that soil behavior is nonlinear, and the deformations are influenced by many factors. Taking this into account, there are various material models are available. The one that is used in our finite element calculations is the HSSmall (Hardening Soil with Small Strain Stiffness - HSS) material model. [6] This material model considers the average increase in stiffness with increasing normal stresses, the changes in shear stresses induced volume change, also takes into account that the stiffness of the soil increases significantly in the range of small deformations.

\subsection{Modelling of structural elements}

The modelling of the load transfer platform, which is a granular layer is not so challenging, as the same material models used for the subsoils can be applied. This layer is defined as a special soil volume.

Using Plaxis 3D finite element software, two basic solutions can be used for pile modelling. Depending on the calculation problem and the available parameters there are advantages and disadvantages of these two methods, which are the following:

- Volume pile concept (VP)

- Embedded beam concept (EB)

\subsubsection{Volume pile concept}

This process allows a precise, complex modelling of the pile geometry, which is a very important question for real simulation of pile-soil interaction along the pile shaft. The material behavior of the pile is described by a linear elastic, non-porous model, and the soil-structure contact is modelled with interface elements with zero thickness. The most important interface property is the strength reduction factor $\left(R_{\text {inter }}\right)$. The interface properties are calculated from the soil properties in the associated data set and the strength reduction factor. [7] For the analysis locally refined mesh generation is required, which induces a high computational demand. It is difficult to extract the structural stresses, so for this reason at the center axis of the piles a beam element with a reduced stiffness is placed (e.g. divided by $10^{6}$ ). The beam has the same deformation as the pile so the stresses can be clearly derived from it.

\subsubsection{Embedded beam concept}

The embedded beam approach was introduced by Sadek and Shahrour [8]. The embedded beam is a structural object composed of beam elements that can be placed in arbitrary direction in the subsoil and that interacts with the subsoil by means of special interface elements. The beam elements are considered to be linear elastic and are defined by the same material parameters as a regular beam element. The interaction may involve a skin resistance as well as a base resistance. The skin friction and the tip force are determined by the relative displacements between the soil and the pile. Although embedded beam does not occupy volume, a particular volume around the pile (elastic zone) is assumed in which plastic soil behavior is excluded. There are virtual nodes at the intersection of the 3 nodded beam element and the soil element with 10 nodes, which does not affect the discretization of the soil. The size of this elastic zone is equal to the real pile diameter which can be defined in the parameter settings. This is the reason why embedded beam behaves like a volume pile. The behavior of the pile is modelled as a beam element, however, the soil-structure interaction are represented by springs connected at the nodes. [7-9]. The parameters of which are calculated from the soil physical properties and derived from the sleeve and base resistance defined as an input data in the program $[10,11]$. This modelling procedure compared to the modelling with volumetric elements results in a shorter computational time and ease of extracting stresses and handling results.

\subsubsection{Comparison of different methods and the hybrid element}

The behavior of different pile models and the distribution of stresses are dissimilar. The maximum normal forces are almost the same in both cases, whereas the distributions 
are different due to the differences in the distribution of the skin resistances and the connection problem at the ends of the EB element. To solve the connection problem in the EB approach, a hybrid pile element $(\mathrm{EB}+\mathrm{VP})$ could be created. In this case, at both ends of the embedded pile, $1 \mathrm{~cm}$ thick VP elements are inserted, which provide appropriate stiffness and load transfer surfaces. Investigated pile models are shown in Fig. 5.

The geometric variants were analyzed for deformations and its impact on structural stresses, particularly in piles awakening to the distribution of normal force and skin resistance, which results are summarized in Fig. 6 and Fig 7. The diagrams show that in the case of differently modelled pile geometries, both the skin resistance and the normal force distribution along the longitudinal axis varies. However, the most important for dimensioning and verifying the suitability of the elements are the maximum normal force values, which are in the same range. For the normal force distribution, finite element analysis approaches the results calculated according to Combarieu's [2] theory.

The biggest disadvantage of piles modeled as a volumetric element is the local mesh refinement, which significantly increases the number of elements and nodes. Due to the element refinement the computing capacity and runtime increases considerably. There is a possibility to approximate a circular cross-section with polygon, reducing computation time so it is more optimal, the result is a more manageable model. This solution is appropriate, if

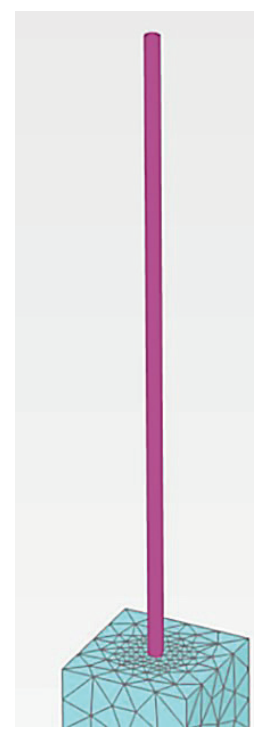

(a)

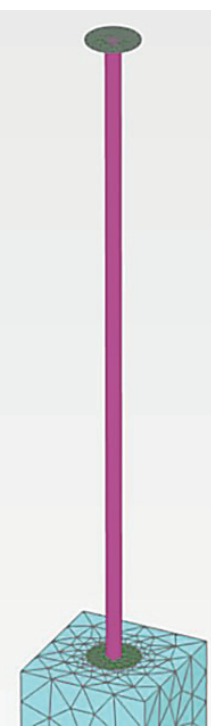

(b)



(c)
Fig. 5 Investigated pile models - Embedded beam (a), Hybrid pile element (b), Volume pile (c)

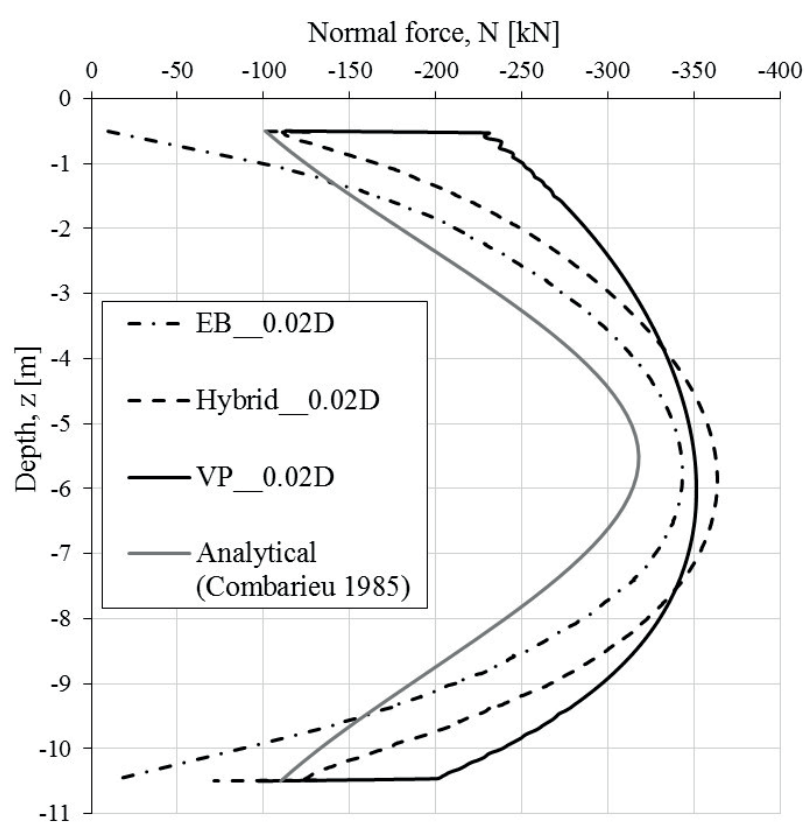

Fig. 6 Influence of different pile modelling options on the distribution of normal force

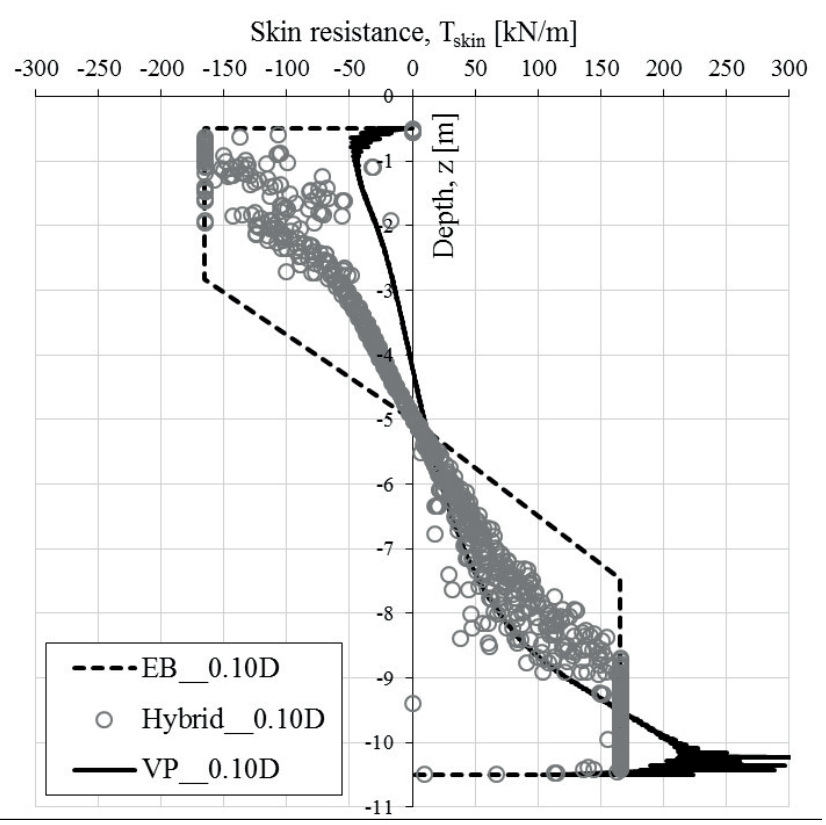

Fig. 7 Influence of different pile modelling options on the distribution of skin resistance

dozens of piles within the model space need to be defined, and if relevant question is the detailed stressing of the structural members (normal force, shear force and torque). Results obtained from finite element calculations presented in Figs. 8. and 9., indicate that it is best to approach the circular cross-section with an octagonal pile, since both stresses and strains the deformations formed are the closest to the results of the reference geometry, which is the cylindrical pile. 


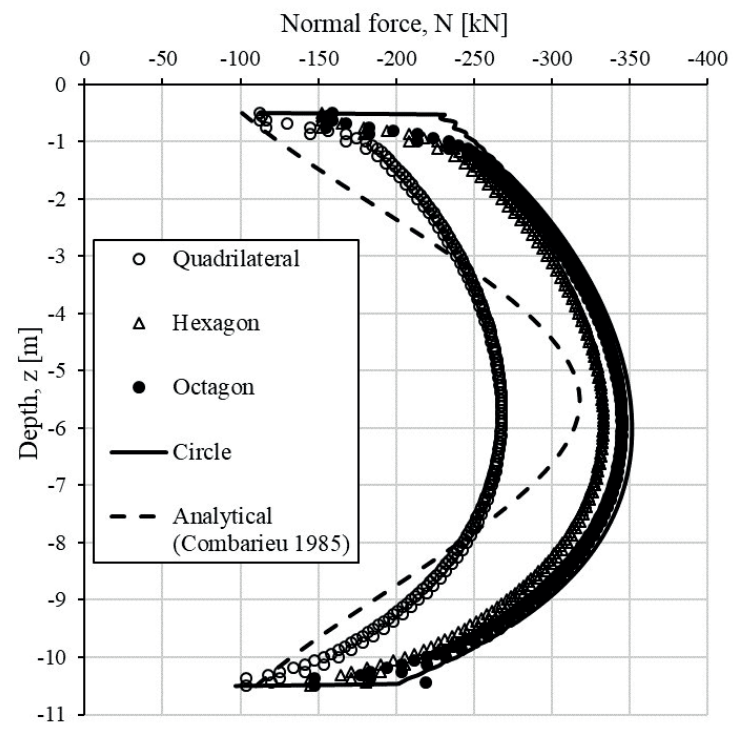

Fig. 8 Normal force distribution in VP with different pile shape

Fig. 9 shows the results of the approximate calculations when the cylindrical shape pile is approached by polygon, where $u_{c i r}=$ settlement in term of cylindrical shape pile; $u_{p o l y}=$ settlement in term of polygonal shape pile; $n_{\text {soil,cir }}=$ number of generated soil elements in Plaxis in term of cylindrical shape pile; $n_{\text {soil,poly }}=$ number of generated soil elements in Plaxis in term of cylindrical shape pile; $n_{\text {node, cir }}=$ number of generated node elements in Plaxis in term of cylindrical shape pile; $n_{\text {nodepoly }}=$ number of generated node elements in Plaxis in term of cylindrical shape pile.

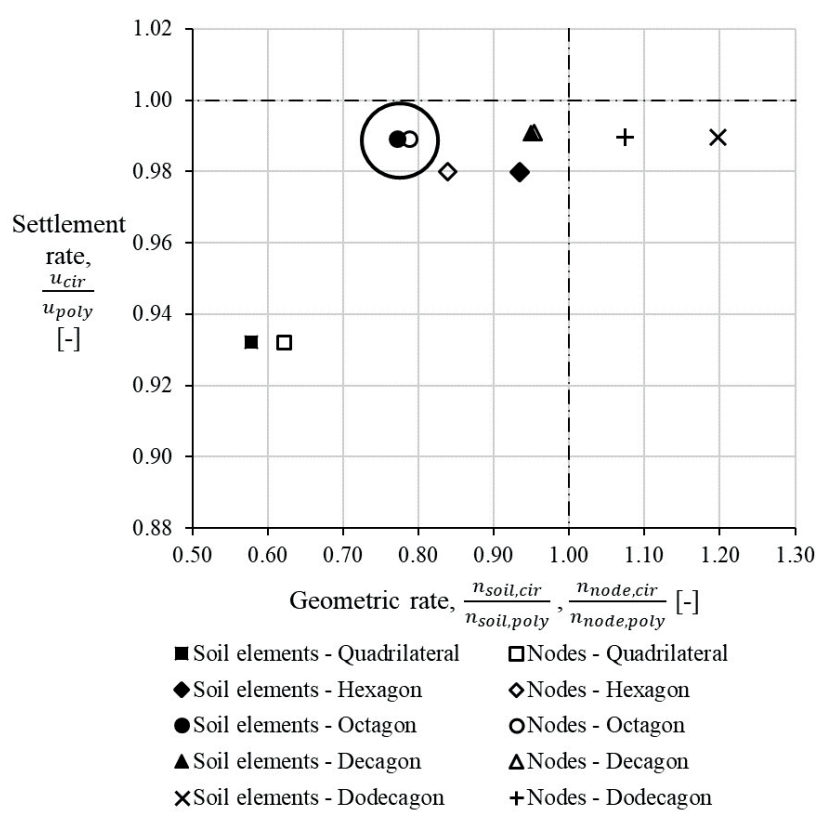

Fig. 9 Effects of soil elements and nodes on settlement in term of different volume pile shapes
In case of foundations, especially true for rigid inclusion foundation system the displacements are the most important results in the design calculations. During the calculations at the upper level of the base slab above the load distribution platform different sizes of prescribed displacements were defined. The surface load required to achieve the prescribed deformations of the baseplate were examined. To examine the mobilization, 0.10D and $0.20 \mathrm{D}$ prescribed displacements were used in the calculations. While the displacements are the most important results in the design calculations, they are summarized in Fig. 10. It is clearly visible that in case of the prescribed displacements with the three different modelling possibility almost the same loads were received, which means that their behavior towards settlement is nearly the same, so there is no significance of which pile geometry was used in the modelling if we are only interested in deformations. There is a significant difference in structural stress, however, the maximum normal force required to dimension the stiffeners its value is almost the same and the neutral planes are also close to each other.

\section{Numerical analysis for redounding the design processes}

There are few construction sites in Hungary where the foundation of the structure was solved by rigid inclusion soil improvement and the settlements and stresses were measured during its operation. Because of the absence

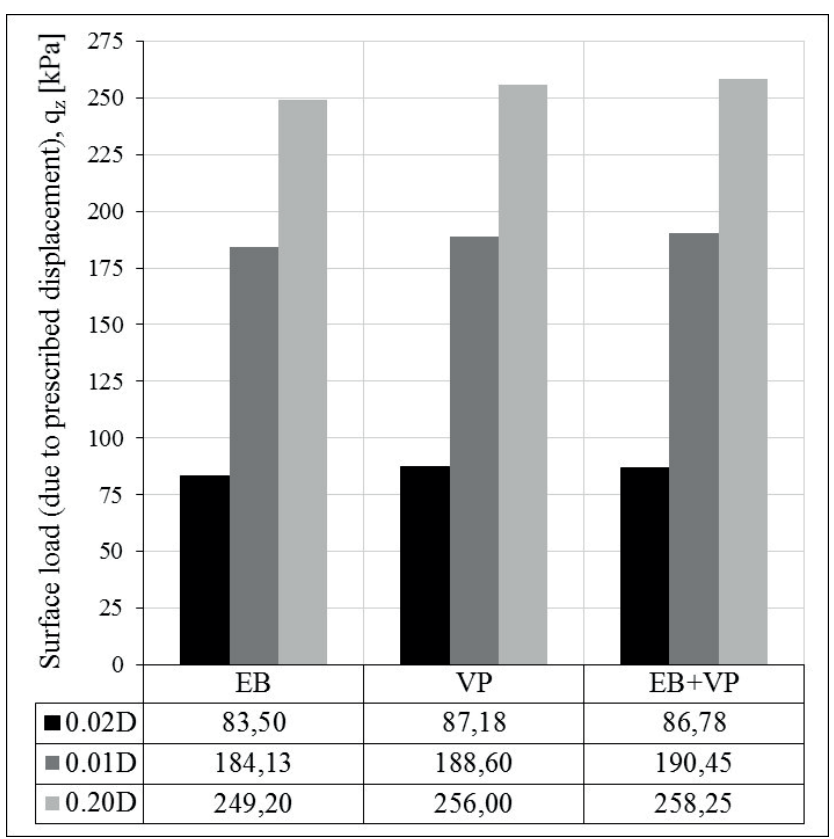

Fig. 10 Sum of forces that are necessary for the prescribed displacements to occur 
of measurement data, a numerical parametric study was conducted, where the components that make up the system and their effect on the settlement were studied. In the parametric study both the effect of the geometric and soil parameters were evaluated.

Among the components that make up the foundation system, we examined the effects of:

- Diameter of the piles

$\mathrm{D}=0.40 \div 0.60 \div 0.80 \mathrm{~m}$

- Structural length of the piles $\mathrm{L}=5 \div 10 \div 15 \div 20 \mathrm{~m}$

- Grid spacing of the piles $\mathrm{R}=2.50 \cdot \mathrm{D} \div 3.75 \cdot \mathrm{D} \div 5.00 \cdot \mathrm{D}$

- Thickness of the load transfer platform $\mathrm{H}=0.00 \cdot(\mathrm{R}-\mathrm{D}) \div 0.20 \cdot(\mathrm{R}-\mathrm{D}) \div 0.40 \cdot(\mathrm{R}-\mathrm{D})$

- Dimension of the raft

$\mathrm{a}=22 \div 36 \div 48 \mathrm{~m}$ $\mathrm{b}=22 \div 36 \div 48 \mathrm{~m}$

- Type of the homogeneous soil

Three types of soils (summarized in Table 1) [6, 12]

The results presented in this article are only limited to clayey silt soil. At the upper plane of the base plate an evenly distributed load of $100 \div 150 \div 200 \div 250 \mathrm{kPa}$ was applied and the response of the foundation system was evaluated.

For most design tasks where concrete reinforcing elements are required improving the compressibility of lowload-bearing subsoils, it is a priority how much the settlements and the differential settlements can be limited by the application of reinforcing elements. With these in mind, the main objective was to focus on the deformations of the soil environment and on the deformation of the baseplate, as well as to evaluate and calculate the improvement caused by the rigid inclusion, which defined as follows:

Table 1 Material properties $[6,12]$

\begin{tabular}{lccc}
\hline Properties & $\begin{array}{c}\text { Clayey silt } \\
\text { (Süffeld } \\
\text { excavation) }\end{array}$ & $\begin{array}{c}\text { Clay } \\
\text { (Element test) }\end{array}$ & $\begin{array}{c}\text { Clay } \\
\text { (Heinenoord } \\
\text { tunnel) }\end{array}$ \\
\hline Material model & HSS & HSS & HSS \\
$g_{\text {unsat }}\left(\mathrm{kN} / \mathrm{m}^{3}\right)$ & 18.5 & 21.0 & 20.0 \\
$g_{\text {sat }}\left(\mathrm{kN} / \mathrm{m}^{3}\right)$ & 21.5 & 22.0 & 20.0 \\
$E_{\text {oed }}{ }^{r e f}(\mathrm{MPa})$ & 6 & 1.05 & 7 \\
$E_{50}{ }^{e f}(\mathrm{MPa})$ & 8.5 & 2.15 & 12 \\
$E_{u r}{ }^{r e f}(\mathrm{MPa})$ & 23 & 11.5 & 35 \\
$\mathrm{~m}(-)$ & 0.9 & 0.8 & 0.9 \\
$\phi^{\prime}\left({ }^{\circ}\right)$ & 32 & 20 & 31 \\
$c_{r e f}^{\prime}(\mathrm{kPa})$ & 30 & 0 & 7 \\
$g_{0.7}(-)$ & $310-4$ & $210-4$ & $210-4$ \\
$G_{0}{ }^{r e f}(\mathrm{MPa})$ & 98.57 & 50 & 131.25 \\
\hline
\end{tabular}

$\eta_{i m p}=\frac{u_{z, a v g, R}}{u_{z, a v g, R I}}$,

where $\eta_{i m p}=$ improvement factor; $u_{z, a v g, R}=$ settlement of the raft without concrete stiffening elements; $u_{z, a v g, R I}=$ settlement of the raft with implementation of rigid inclusion. The improvement factor was chosen as a benchmark, because there are many analytical methods to calculate the settlement of a mat foundation, as well as simpler computer software can quickly determine the maximum and average settlement in case of steady loads.

In Fig. 11 the improvement factor is presented as a function of the pile length, different loads $(100 \div 150 \div$ $200 \div 250 \mathrm{kPa}$ distributed load) and grid distances $(2.50$ $\div 3.75 \div 5.00 \mathrm{D})$ were analyzed. The figure shows that at $100 \mathrm{kPa}$, there is no significant increase in improvement factor, which also means using concrete reinforcing elements at this load intensity the subsidence does not decrease significantly by increasing the length of the elements and decreasing the raster spacing, the improvement factor increases almost linearly with length. Much more outstanding the improvement at $250 \mathrm{kPa}$ load (but also at $150 \div 200 \mathrm{kPa}$ load in some cases). The relationship in this range between the improvement factor and the stiffener length can be best approached by a logarithmic function.

A similar trend can be seen in the diagram in Fig. 12, where the improvement was plotted as a function of the length and diameter of the stiffeners factor at different load levels. Due to the shallow boundary depth the 100 $\mathrm{kPa}$ load, it is not significant in this case either increase in the improvement factor, while increasing the load is already visible you can see the effectiveness of the foundation system compared to traditional slab foundations.

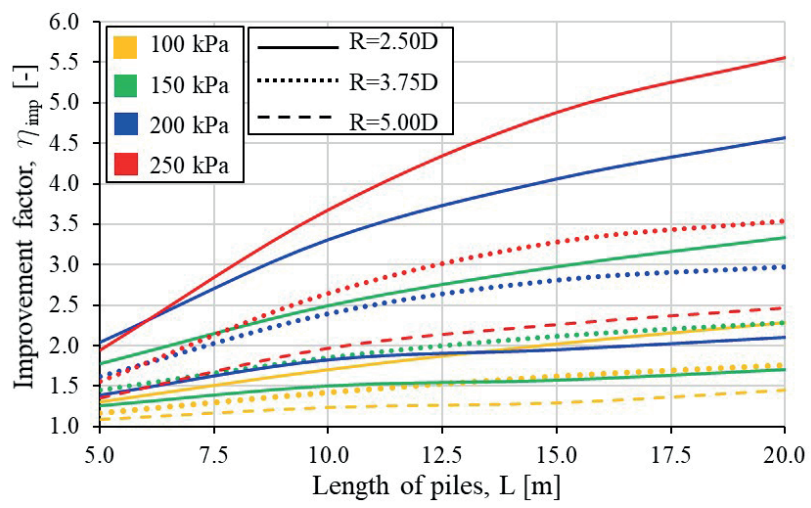

Fig. 11 Length of stiffeners and effect of raster spacing on improvement factor 


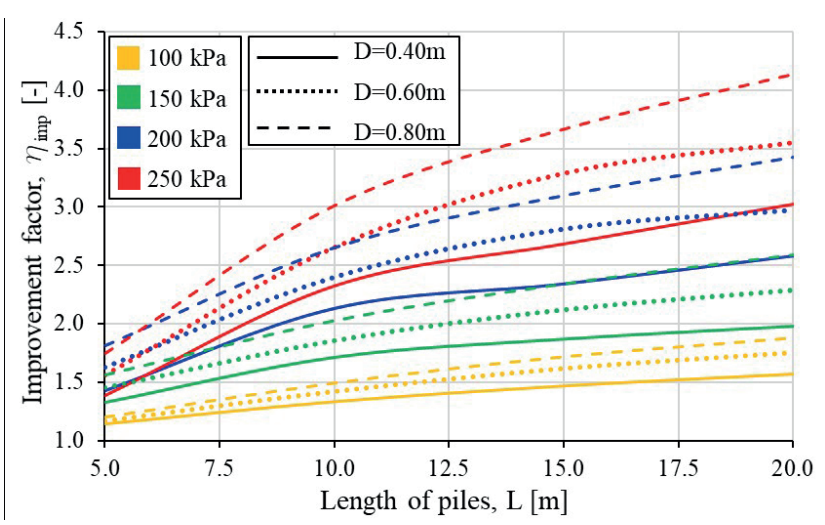

Fig. 12 Length of stiffeners and effect of the pile diameter on improvement factor



Fig. 13 Improvement factor as a function of length of the stiffeners as well as the grid spacing

Fig. 13 shows the change in the improvement factor over the length of the stiffeners, raster spacing and diameter (in the figure, to ease clarity only $D=0.60 \mathrm{~m}$ diameter results are included). On the horizontal axis the ration of $A_{c}$ over $A_{R}$ divided by the length of the stiffener is presented, where $A_{c}$ is the cross-sectional area of the stiffener and $A_{R}$ is the grid area for one stiffener. Improvements experienced at different load levels are divided to zones, which are colored differently. The figure clearly shows that increasing the grid spacing decreases the improvement factor, the values on the horizontal axis move towards the origin. Because the position of the piles increases relative to one another, the area of the mat foundation per pile ratio increases compared to the area of the whole foundation slab. Excessive grid spacing can drastically reduce the effectiveness of the rigid inclusion soil improvement method.

In Fig. 14 the variation of the thickness of the load distribution layer and the structural length of the piles effect on the system's improvement factor was analyzed. In Fig. 15 the values of the maximum moments awakening in the base plate depending on the thickness of the load distribution layer (diameter of stiffeners, distance between the piles centre line and the thickness of the base slab was

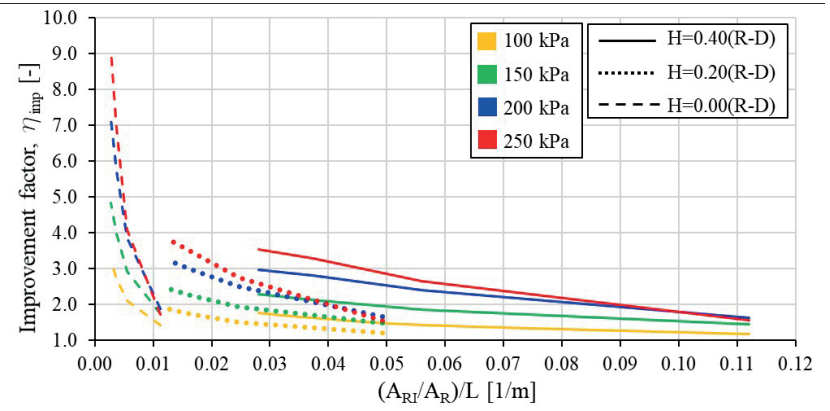

Fig. 14 The effect of the load distribution layer's thickness and pile length on the improvement factor



Fig. 15 The effect of the load distribution layer's thickness and pile length on the maximum moment that awakens in the raft

constant, $D=0.60 \mathrm{~m}, R=3.75 \cdot \mathrm{D}, v=0.30 \mathrm{~m}$ ). In the figures it is visible, if only the settlement limitation and efficiency of the foundation structure would be the question, then a pile foundation, or piled raft foundation (removing the bedding layer from the system) the deformations can be reduced to a much greater extent. From the structural point of view a too thin load distribution layer, would result the significant increase of bending moments in the base slab, which would lead to the need of increasing its thickness, furthermore bigger stiffener piles or more reinforcement would be needed. Another consideration may be the design of the structure to earthquake load, where the competitiveness and cost-effectiveness of rigid inclusion soil enhancement technology unquestionable compared to traditional deep foundations. From the stiffeners to the base plate, no extra stresses will be carried over, as they can move independently due to the damping effect of the load bearing layer.

\section{Conclusions}

With the acceleration of urbanization during real estate investments and developments there are more and more areas used for construction that are considered as geotechnically unfavorable sites. In these design areas, the soil improvement procedures take precedence over traditional deep foundation technologies. The soil improvement 
techniques improve the overall geotechnical parameters of the poor bearing capacity subsoils, they secure the adequacy and stability of the superstructures. In most cases, there is no sophisticated design procedure for soil reinforcement methods, only guidelines, suggestions and experience-based relationships to support the engineers daily work. This is no different with the rigid inclusion soil improvement method. Accurate sizing, detailed examination of structural settlements and settlement differences lead to numerical analysis, where the correct modeling strategy must be carefully selected from the capabilities of the target software. Due to the complexity of the system, the influence of several geometric parameters on the structural behavior of each component should be investigated and analyzed.

Since the rigid inclusion foundation is also a soil improvement technique, the most important question is the displacement behavior of the system, which could be reached with each pile modelling options, so during the modeling process (especially during the 3D geometrical definition) the suggested version is the embedded beam approach due to the relatively short calculation time.

\section{References}

[1] Varaksin, S., Hamidi, B., Huybrechts, N., Denies, N. "Ground Improvement vs. Pile Foundations?", ISSMGE - ETC 3 International Symposium on Design of Piles in Europe, Leuven, Belgium, April, 28-29, 2016. [online] Available at: https://www.cstc.be/homepage/download.cfm?lang $=$ en $\&$ dtype $=$ research $\&$ doc $=$ GROUND_ IMPROVEMENT_VS_PILE_FOUNDATIONS.pdf [Accessed: 2019. December 10]

[2] Press des Pontos "ASIRI National Project, Recommendations for the design, construction and control of rigid inclusions ground improvements" [online] Available at: https://www.presses-desponts.fr/notre-librairie/329-asiri-national-project.html [Accessed: 2019. December 10]

[3] Móczár, B., Mahler, A., Lődör, K., Bán, Z. "Back analysis of settlements beneath the foundation of a sugar silo by $3 \mathrm{D}$ finite element method", Plaxis Bulletin, 39, pp. 12-17, 2016. [pdf] Available at: file://C:/Users/user/Downloads/Plaxis_Bulletin_Iss39_Art2_Back_analysis_of_settlements_beneath_the_foundation_of_a_ sugar_silo.pdf [Accessed: 2019. December 10]

[4] Stacho, J., Sulovska, M. "Numerical Analysis of Soil Improvement for a Foundation of a Factory Using Stone Columns Made of Different Types of Coarse-grained Materials", Periodica Polytechnica Civil Engineering, 63(3), pp. 795-803, 2019. https://doi.org/10.3311/PPci.13727

[5] Jenck, O., Dias, D., Kastner, R. "Soft ground improvement by vertical rigid piles two-dimensional physical modelling and comparison with current design methods", Soils and Foundations, 45(6), pp. 15-30, 2005.

https://doi.org/10.3208/sandf.45.15
The relationship between the improvement factor and the length of the inclusions can be best approached by a logarithmic function, where the improvement factor is the ratio of the settlement with and without concrete stiffening elements. The numerical calculation results clearly shows that increasing the grid spacing decreases the improvement factor. Because the position of the piles increases relative to one another, the area of the mat foundation per pile ratio increases compared to the area of the whole foundation slab. Excessive grid spacing can drastically reduce the effectiveness of the rigid inclusion soil improvement method. In case of earthquake design the competitiveness and cost-effectiveness of rigid inclusion soil enhancement technology unquestionable compared to traditional deep foundations, because no extra stresses will be transferred from the inclusions to the raft, they can move independently due to the damping effect of the load bearing layer.

[6] Benz, T. "Small-Strain Stiffness of Soils and its Numerical Consequences", PhD Thesis, University of Stuttgart, 2007. [pdf] Available at: https://www.plaxis.com/content/uploads/import/kb/kbpublications/PhDthesis_TBenz.pdf [Accessed: 2019. December 10]

[7] Tschuchnigg, F. "3D Finite Element Modelling of Deep Foundations Employing an Embedded Pile Foundation", PhD Dissertation, Graz University of Technology, 2013.

[8] Sadek, M., Shahrour, I. "A three dimensional embedded beam element for reinforced geomaterials", International Journal for Numerical and Analytical Methods in Geomechanics, 28(9), pp. 931-946, 2004.

https://doi.org/10.1002/nag.357

[9] Marjanović, M., Vukićević, M., König, D., Schanz, T., Schäfer, R. "Modeling of laterally loaded piles using embedded beam elements", In: 4th International Conference "Contemporary Achievements in Civil Engineering", Subotica, Serbia, 2016, pp. 349-358. https://doi.org/10.14415/konferencijaGFS2016.035

[10] Mahler, A. "Use of Cone Penetration Test in Pile Design", Periodica Polytechnica Civil Engineering, 47(2), pp. 189-197, 2003. [online] Available at: https://pp.bme.hu/ci/article/view/614 [Accessed: 2019. December 10]

[11] Szepesházi, R., Scheuring, F. "Practical briefing for the pile design and testing - Hungarian practice", In: ISSMGE - ETC 3 International Symposium on Design of Piles in Europe, Leuven, Belgium, 2016, pp. 199-211.

[12] Rémai, Zs. "Correlation of undrained shear strength and CPT resistance", Periodica Polytechnica Civil Engineering, 57(1), pp. 39-44, 2013.

https://doi.org/10.3311/PPci.2140 